\title{
High-pressure homogenization and high hydrostatic pressure processing of human milk: Preservation of immunological components for human milk banks
}

\author{
A. Irazusta, ${ }^{1 *} \odot$ C. Rodríguez-Camejo, ${ }^{2 *} \odot$ S. Jorcin, ${ }^{1} \odot$ A. Puyol, ${ }^{3}$ L. Fazio, ${ }^{3}$ F. Arias,${ }^{2}$ M. Castro,${ }^{4}$ \\ A. Hernández, ${ }^{2}$ (i) and T. López-Pedemonte ${ }^{1} \dagger$ (1) \\ 'Área de Tecnología de Alimentos, Departamento de Ciencia y Tecnología de Alimentos, Facultad de Química, Universidad de la República, \\ Montevideo, Uruguay 11800 \\ ${ }^{2}$ Cátedra de Inmunología, Instituto de Química Biológica, Facultad de Ciencias-Área Inmunología, Departamento de Biociencias, \\ Facultad de Química, Instituto de Higiene, Universidad de la República, Montevideo, Uruguay 11600 \\ ${ }^{3}$ Banco de Leche "Ruben Panizza," Centro Hospitalario Pereira Rossell, Administración de los Servicios de Salud del Estado, Montevideo, \\ Uruguay 11600 \\ ${ }^{4}$ Hospital de la Mujer, Centro Hospitalario Pereira Rossell, Administración de los Servicios de Salud del Estado, Montevideo, \\ Uruguay 11600
}

\begin{abstract}
Human milk (HM) constitutes the first immunological barrier and the main source of nutrients and bioactive components for newborns. Immune factors comprise up to $10 \%$ of the protein content in HM, where antibodies are the major components (mainly $\operatorname{IgA}, \operatorname{IgG}$, and IgM). In addition, antibacterial enzymes such as lysozyme and immunoregulatory factors such as soluble cluster of differentiation 14 (sCD14) and transforming growth factor $\beta 2$ (TGF- $\beta 2$ ) are also present and play important roles in the protection of the infant's health. Donor milk processed in HM banks by Holder pasteurization ( $\left.\mathrm{HoP} ; 62.5^{\circ} \mathrm{C}, 30 \mathrm{~min}\right)$ is a safe and valuable resource for preterm newborns that are hospitalized, but is reduced in major immunological components due to thermal inactivation. We hypothesized that high hydrostatic pressure (HHP) and high-pressure homogenization $(\mathrm{HPH})$ are 2 processes that can be used on HM to reduce total bacteria counts while retaining immunological components. We studied the effects of HHP (400, 450, and $500 \mathrm{MPa}$ for 5 min applied at $20^{\circ} \mathrm{C}$ ) and $\mathrm{HPH}(200,250$, and $300 \mathrm{MPa}$, milk inlet temperature of $20^{\circ} \mathrm{C}$ ) applied to mature $\mathrm{HM}$, on microbiological and immunological markers ( $\operatorname{IgA} \operatorname{IgG}$, IgM, sCD14, and TGF-32), and compared them with those of traditional HoP in HM samples from healthy donors. The HHP processing between 400 and $500 \mathrm{MPa}$ at $20^{\circ} \mathrm{C}$ reduced counts of coliform and total aerobic bacteria to undetectable levels $(<1.0 \log \mathrm{cfu} / \mathrm{mL})$
\end{abstract}

Received September 9, 2019.

Accepted February 19, 2020.

*These authors contributed equally to this work.

†Corresponding author: tlopez@fq.edu.uy while achieving approximately 100\% of immunological component retention. In particular, comparing median percentages of retention of immunological components for $450 \mathrm{MPa}$ versus $\mathrm{HoP}$, we found 101.5 versus $50.5 \%$ for IgA, 89.5 versus $26.0 \%$ for IgM, 104.5 versus $75.5 \%$ for IgG, 125.0 versus $72.5 \%$ for lysozyme, 50.6 versus $0.1 \%$ for sCD14, and 88.5 versus $61.1 \%$ for TGF- $\beta 2$, respectively. Regarding $\mathrm{HPH}$ processing, at a pressure of $250 \mathrm{MPa}$ and inlet temperature of $20^{\circ} \mathrm{C}$, the process showed good potential to reduce coliforms to undetectable levels and total aerobic bacteria to levels slightly above those obtained by HoP. The median percentages of retention of immunological markers for $\mathrm{HPH}$ versus HoP were 71.5 versus $52.0 \%, 71.0$ versus $27.0 \%, 104.0$ versus $66.5 \%$, and 30.9 versus $0.2 \%$, for $\operatorname{IgA}, \operatorname{IgM}, \operatorname{IgG}$, and sCD14, respectively; results did not significantly differ for lysozyme and TGF- $\beta 2$. The HPH at $300 \mathrm{MPa}$ produced higher inactivation of immunological components, similar to values achieved with HoP.

Key words: high hydrostatic pressure, high-pressure homogenization, human milk bank, immunological component, microbiological safety

\section{INTRODUCTION}

Human milk (HM) constitutes the only source of nutrients and bioactive components for most newborns, and the first immunological barrier. Immune factors comprise up to $10 \%$ of the protein content in HM (Affolter et al., 2016) with secretory IgA (almost 90\%), IgG, and IgM constituting major antibodies. Human milk also contains antibacterial enzymes including lactoferrin, lysozyme, and lactoperoxidase (Sousa et al., 2014). In addition to defenses, immune components contribute to the maturation of the infant immune 
system and regulation of immune response (Weaver, 1997; Lawrence and Pane, 2007). Several soluble receptors involved in the modulation of gut inflammation are also present in HM. Cluster of differentiation 14 is a membrane receptor that is secreted (sCD14) upon cell activation and regulates the function of epithelial cells by interfering with endogenous or microbial pro-inflammatory signaling (Baroncelli et al., 2018). Transforming growth factor $\beta$ (TGF- $\beta$ ) is a cytokine capable of increasing the production of IgA, contributing to oral tolerance mechanisms (Oddy and Rosales, 2010) and reinforcing the epithelial barrier by acting as a growth factor. The main isoform in HM is TGF- $\beta 2$ (Kondo et al., 2011).

The bioactive properties of milk are critical for preterm newborns (born before wk 37 of gestation), who are highly susceptible to infections and inflammatory diseases (Pineda, 2011). During hospitalization at intensive care units, preterm mothers may not be able to provide enough milk (Eidelman and Schanler, 2012), and stored HM is the best alternative, even better than bovine milk formulas (Arnold, 2006). Donated milk processed in human milk banks (HMB) is thus a valuable resource for improving the preterm infant's health outcome.

Pasteurization is a process frequently used in HMB to ensure microbiological safety. Holder pasteurization (HoP) is the reference method for most HMB and consists of applying low-temperature/long-time processing conditions $\left(62.5^{\circ} \mathrm{C}, 30 \mathrm{~min}\right.$; Updegrove, 2005 ; Hartmann et al., 2007). Although very efficient in inactivating pathogens, HoP degrades immunoglobulins, lysozyme, vitamin $\mathrm{C}$, and other bioactive factors (Koenig et al., 2005; Romeu-Nadal et al., 2008; Moltó-Puigmartí et al., 2011). An adaptation of HTST pasteurization used in the dairy industry has recently been applied to HMB samples with promising results (Giribaldi et al., 2016; Escuder-Vieco et al., 2018). However, nonthermal technologies can be considered to improve the bioactive and nutritional value of HM. High hydrostatic pressure (HHP) is already used in the food industry mainly to extend shelf life, and consists of subjecting the packaged sample to pressures of 200 to 1,400 $\mathrm{MPa}$, which distribute evenly throughout the sample (Cheftel, 1995; Evelyn and Silva, 2019). Because HHP is mostly applied to packaged samples, post-processing recontamination hardly occurs. High hydrostatic pressure proved effective to inactivate a variety of pathogens in milk (Patterson and Kilpatrick, 1998; Gervilla et al., 2000). The HHP at 200 to $600 \mathrm{MPa}$ and mild temperatures has been recently applied to bottled HM, showing encouraging results for microbiological safety and preservation of major immune molecules including antibodies and important nutrients such as vitamins and fatty acids (Murchie et al., 2005; Permanyer et al., 2010; Moltó-Puigmartí et al., 2011; Delgado et al., 2013; Sousa et al., 2014). Nevertheless, information is lacking regarding the effect of HHP on relevant immune factors.

High-pressure homogenization $(\mathbf{H P H})$ is a process currently studied in different liquid foods. High-pressure homogenization consists of forcing the fluid through the gap of the valve of few micrometers, reaching pressures of 100 to $400 \mathrm{MPa}$ (Dumay et al., 2013). In contrast to HHP, contamination of fluid foods exiting the outlet of HPH equipment can occur unless packaged under aseptic conditions. For bovine milk, HPH proved effective to inactivate spoilage and pathogenic microorganisms (Vachon et al., 2002; Briñez et al., 2006). Pereda et al. (2006) reported a reduction of $4 \mathrm{log} \mathrm{cfu} / \mathrm{mL}$ in total counts at $300 \mathrm{MPa}$, for inlet temperatures $\left(\mathbf{T}_{\text {in }}\right)$ of 30 and $40^{\circ} \mathrm{C}$. Pressures of 300 to $400 \mathrm{MPa}$ at $\mathrm{T}_{\text {in }}$ of $75^{\circ} \mathrm{C}$ inactivated up to $5.0 \log \mathrm{cfu} / \mathrm{mL}$ of Bacillus spores and at $\mathrm{T}_{\mathrm{in}}$ of $45^{\circ} \mathrm{C}$ maintained levels of nicotinamide, thiamine, riboflavin, and vitamin $\mathrm{C}$ present in raw milk (Amador-Espejo et al., 2014, 2015).

Previous research suggests that either HPP or HPH are potential processing technologies to substitute HoP in the preservation of high-quality HM. The aim of this study was to evaluate the effects of HHP and HPH applied to mature HM (produced 1 mo after delivery), and compare its safety and quality to HM processed using HoP. To do this, microbiological (total and coliform counts) and immunological markers (IgA, IgG, IgM, sCD14, and TGF- $\beta 2$ ) in HM were monitored before and after processing using HHP, HPH, and HoP.

\section{MATERIALS AND METHODS}

\section{Obtaining of Breast Milk Samples}

The samples were obtained from healthy mothers (19-35 yr old) who donated milk to the HMB of the Pereira Rossell Hospital (Montevideo, Uruguay). All volunteers met the HMB criteria and according to milk availability, donated $50 \mathrm{~mL}$ of milk to this work. The protocol was approved by the Research Ethics Board of the Pereira Rossell Hospital. All samples were obtained at approximately $30 \mathrm{~d}$ after parturition (mature milk). The samples remained frozen at $-80^{\circ} \mathrm{C}$ until analysis.

\section{Experimental Design}

Each sample for study was obtained by mixing 50 $\mathrm{mL}$ of milk derived from individual donors (pooled milk samples from 5 to 10 mothers). A total of 16 pooled samples were prepared to be used for HHP selected conditions, $\mathrm{HPH}$, and HoP processing. All pooled samples 


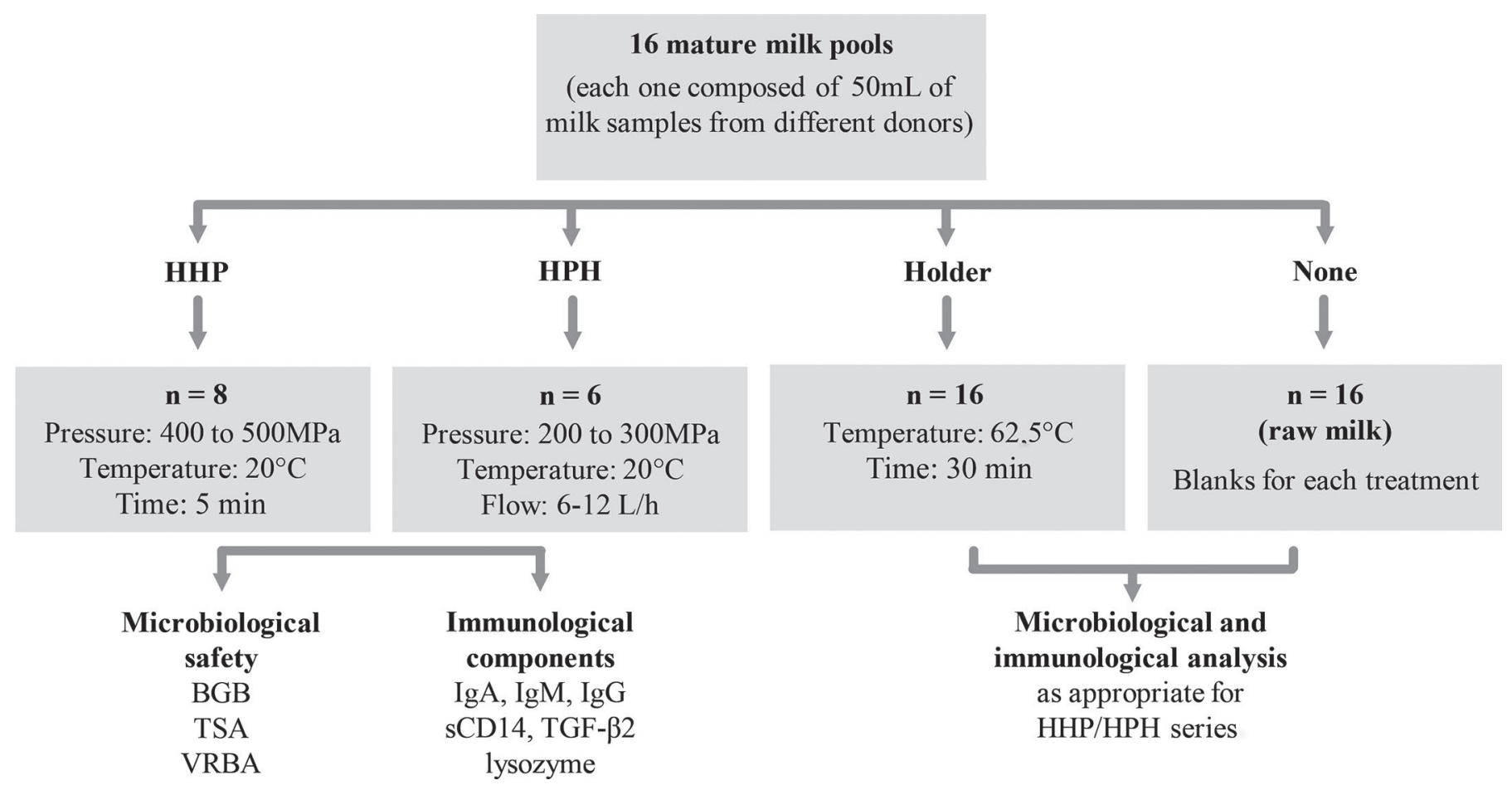

Figure 1. Schematic diagram of the experimental design. BGB = bright green bile broth; TSA = tryptic soy agar; VRBA = violet red bile glucose agar; sCD14 = soluble cluster of differentiation 14 ; TGF- $\beta 2=$ transforming growth factor $\beta 2$; HHP $=$ high hydrostatic pressure; HPH = high-pressure homogenization.

were submitted to HoP and an aliquot not submitted to any treatment was considered as the reference (raw milk). Eight $(\mathrm{n}=8)$ and $6(\mathrm{n}=6)$ different pooled samples were used for HHP and HPH treatments, respectively. For HHP screening conditions we formerly used 2 additional pooled samples. Before submitting the samples to any processing conditions, they were thawed under refrigeration conditions. Pooled samples were further analyzed according to Figure 1.

\section{HHP Processing}

The HHP treatments were performed using a highpressure unit model S-IL-100-250-09W (HP Food Processor, Stansted Fluid Power, Ltd., Harlow, UK) located in a pilot food plant (Laboratorio Tecnológico del Uruguay, LATU, Montevideo, Uruguay). The pressure chamber of $2 \mathrm{~L}$ volume has a $100-\mathrm{mm}$ bore internal diameter, $250 \mathrm{~mm}$ long, and has the inside of the canister to hold the samples. The vessel body and the pressure transmitting fluid (water) were kept at treatment temperature by circulating water through an integral heat transfer jacket fitted to the outside of the high-pressure barrel assembly. The temperature of the pressure transmitting fluid was monitored with a thermocouple positioned in the bottom of the chamber. Five milliliters of pooled HM samples was packed in sterile polyethylene bags (Stomacher bags, model BA6041; Seward, London, UK), taking extra care to remove the air inside each package before sealing them to prevent collapse of the bags due to pressure. Immediately before the treatment, HM samples were tempered in a water bath (Stewart, SBS40, Bibby Scientific Ltd., Stone, UK) set at the processing temperature. On each run 4 HM samples were placed inside the canister, stabilized at the initial treatment temperature, and immediately submitted to a 5-min HHP cycle. Pressure levels were monitored with digital and analog indicators. For pressure and temperature conditions, see HHP Screening Series and HHP Selected Conditions Series.

HHP Screening Series. Based on previous studies (Murchie et al., 2005; Delgado et al., 2013; Sousa et al., 2014), a screening of pressures and initial temperatures $\left(10,20\right.$, and $\left.30^{\circ} \mathrm{C}\right)$ was carried out. High pressures tested were 250, 300, 350,400,450, 500, and $600 \mathrm{MPa}$ for 5 min. Each HHP condition was applied at least in 2 independent replicates. Raw milk samples not processed using HHP were used to determine initial values for each HM sample. Samples were analyzed for IgA and IgM and the presence of coliforms. The results for IgA and IgM are shown in Appendix Figure A1. Overall, the retention values obtained in HM were not relevantly affected by the initial processing temperatures. All pressure levels tested produced HM with high IgA and 
HHP

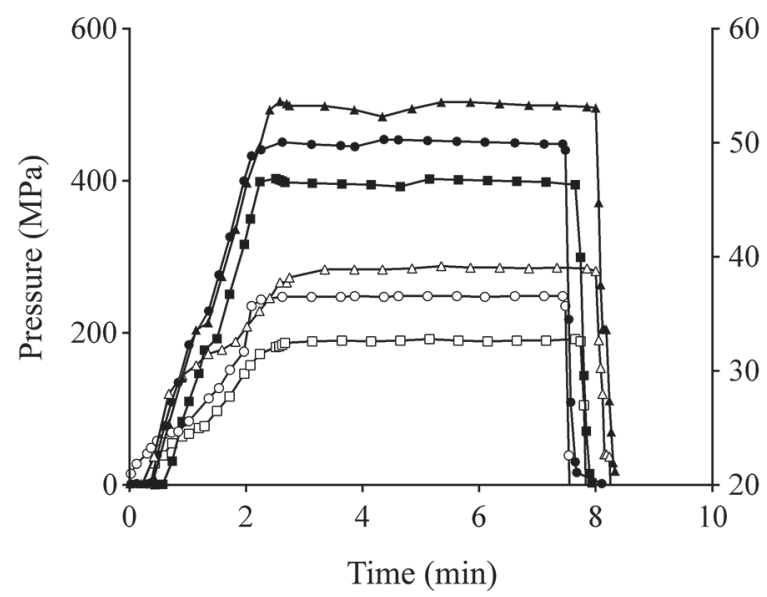

HoP

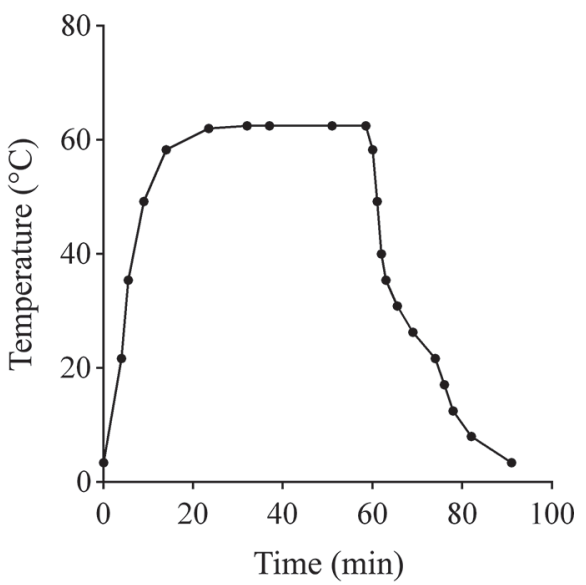

Figure 2. Example of pressure-temperature recordings for high hydrostatic pressure (HHP) treatments applied for 5 min at $20^{\circ} \mathrm{C}(400,450$, and $500 \mathrm{MPa})$ and Holder pasteurization (HoP).

IgM retentions. Due to excessive reduction in $\operatorname{IgA}$ and IgM retention, the processing of HM using HHP at 600 $\mathrm{MPa}$ was discarded for further testing. The processing of HM using HHP at $\leq 300 \mathrm{MPa}$ was also discarded due to coliform detection using standard microbiological assays. Consequently, we decided to continue this work using 400, 450, and $500 \mathrm{MPa}$, applied for 5 min at $20^{\circ} \mathrm{C}$ as initial processing temperature.

HHP Selected Conditions Series. Pressure selected conditions were 400, 450, and $500 \mathrm{MPa}$; initial treatment temperature $20^{\circ} \mathrm{C}$; time at target pressures 5 min. Each treatment was conducted 2 separate times for each of the $3 \mathrm{HM}$ pool samples. Raw milk samples not submitted to HHP were used as controls for each HM sample. A typical pressure-temperature recording of the HHP selected conditions is illustrated in Figure 2. Processing variables are shown in Table 1.

Samples were assessed for all immunological components and microbiological markers described.

\section{HPH Processing}

The HPH equipment used for the trials was a model 11300 FPG bench-top system by Stansted Fluid Power Ltd. (Stansted, UK), located at the pilot plant of the LATU. The machine has a high-pressure valve made of resistant ceramics and is able to reach $400 \mathrm{MPa}$. A second pneumatic valve located after the first one is able to support $50 \mathrm{MPa}$. This valve was not used in our study. The high-pressure system consists of 2 intensifiers driven by a hydraulic pump. To avoid loss of homogenization performance due to temperature increase and rapid expansions or contractions of the high-pressure valve, the system is refrigerated by constant recirculation of water in an external jacket built around it. Before each process, the machine was rinsed with water, washed with $5 \% \mathrm{vol} / \mathrm{vol}$ solution of neutral detergent during $20 \mathrm{~min}$, rinsed with hot water $\left(70^{\circ} \mathrm{C}\right)$, sanitized with $70 \% \mathrm{vol} / \mathrm{vol}$ ethanol in water, and then rinsed with sterile water. Before each treatment, the samples were tempered in a water bath at $20^{\circ} \mathrm{C}$ (Stewart, SBS40, Bibby Scientific Ltd.). Then, $300 \mathrm{~mL}$ of $\mathrm{HM}$ pooled samples were loaded into a plastic container and then pumped through the machine at $20 \pm 2^{\circ} \mathrm{C}$ (inlet temperature) and pressures of 200, 250, and 300 MPa. Immediately after passing through the valve, the samples were cooled down in a custom-made heat exchanger jacket (built around the pipeline connecting the high-pressure valve assembly with the outlet) with water at $4^{\circ} \mathrm{C}$, collected at $25 \pm 5^{\circ} \mathrm{C}$ into sterile containers of $50 \mathrm{~mL}$, and stored at $4^{\circ} \mathrm{C}$. The HM samples were $\mathrm{HPH}$ processed 3 independent times as described above. Control samples were obtained by processing raw milk though the homogenizer at 0.1 MPa. Raw milk samples not processed using HHP were used to determine initial values for each HM sample.

\section{Thermal Processing by HoP}

For each HPH and HHP treatment, a thermal control sample of each sample was obtained by conventional HoP using a custom-made water bath able to process 29 bottles of $150 \mathrm{~mL}$ each (Dexin Grupo Químico S.R.L, Montevideo, Uruguay). This process consisted in treating the samples at $62.5^{\circ} \mathrm{C}$ for $30 \mathrm{~min}$ following the guidelines of the Brazilian Network of HMB 


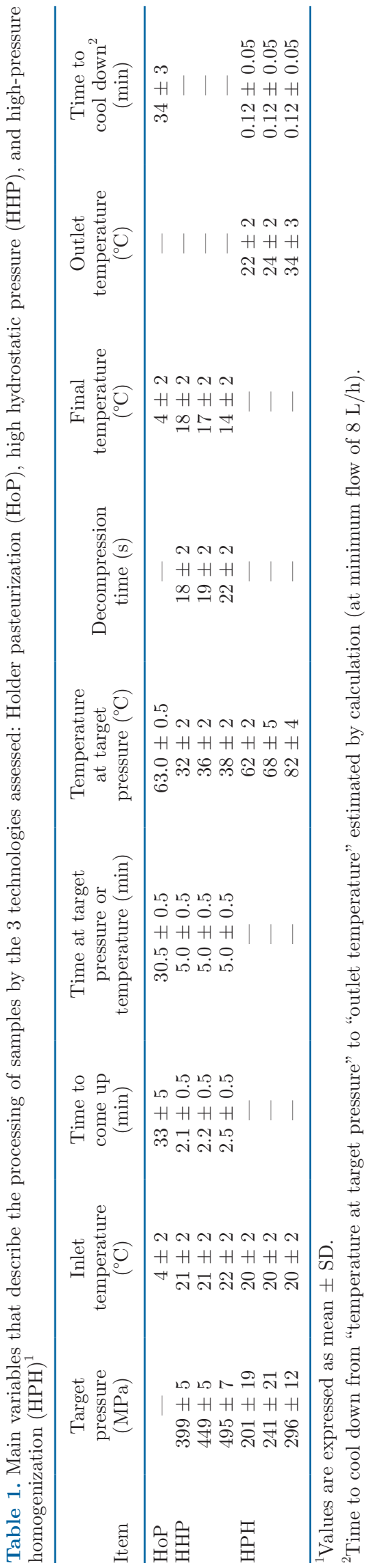

(Agência Nacional de Vigilância Sanitaria, 2008). The glass bottles were partially submerged in water and were continuously stirred using the water bath linear shaker to allow for homogeneous temperature distribution; a milk bottle with a temperature probe was placed in the middle of the bath (representing the coldest point). Then, the samples were cooled to room temperature with tap water circulating continuously in the equipment, and finally to $4^{\circ} \mathrm{C}$ with a bath of water/ice (milk temperature increased from 25 to $62.5^{\circ} \mathrm{C}$ in approximately $20 \mathrm{~min}$; milk temperature dropped from 62.5 to $30^{\circ} \mathrm{C}$ in approximately $6.5 \mathrm{~min}$ and to $25^{\circ} \mathrm{C}$ in approximately $12.5 \mathrm{~min}$ ). The device uses a microprocessor to control the temperature of the milk, assisted by the external probe in the control bottle. A permanent recording of the temperature of the milk, times, and dates are available for every batch; the main parameters can be observed in Table 1. All HM pool samples were submitted to HoP 3 times. The HoP was carried out at the HMB of the Pereira Rossell Hospital (Montevideo, Uruguay) supervised by our research team. A typical temperature-time recording of the HoP conditions applied can be observed in Figure 2.

\section{HM Composition Analysis}

The protein, lactose, and fat content were evaluated in raw samples of milk with an ultrasonic milk analyzer calibrated for HM at the HMB (Lactoscan SLP, Milkotronic Ltd., Nova Zagora, Bulgaria). The calibration of the Lactoscan SLP for analysis of HM was done with HM samples analyzed by standard methods: (1) gravimetric analysis for fat determination (ISO, 2010); (2) determination of lactose content by the chloramine $\mathrm{T}$ method (IDF, 1974); and (3) protein determination by Kjeldahl method (ISO, 2014). These analyses were performed by LATU. Before milk analysis at the $\mathrm{HMB}$, an additional routine calibration check is usually performed using the reference solutions, following the manufacturer's instructions. The accuracies for fat, protein, and lactose determinations were $\pm 0.06,0.15$, and $0.20 \%$, respectively. The energy supply for HM samples (calories $/ \mathrm{mL}$ ) was calculated as $9 \times$ lipids $(\mathrm{mg} / \mathrm{mL})+$ $4 \times$ proteins $(\mathrm{mg} / \mathrm{mL})+4 \times$ lactose $(\mathrm{mg} / \mathrm{mL})$.

\section{Determination of Immunoglobulin Content}

For analysis of immune components, the aqueous fraction (AF) of HM was separated for each sample as previously described. Briefly, once thawed the samples were centrifuged at $4^{\circ} \mathrm{C}$ in 2 sequential steps to obtain the AF: $1,000 \mathrm{rpm}$ for $10 \mathrm{~min}$ and then 10,000 rpm for $30 \mathrm{~min}$ to remove the lipid phase (Rodríguez-Camejo et al., 2020). 
Immunoglobulin A, $\operatorname{IgM}$, and $\operatorname{IgG}$ were quantified in quadruplicate wells by ELISA. The coefficients of variation for ELISA were always lower than 15\%. Briefly, 96-well plates (Greiner, Frickenhausen, Germany) were coated with the appropriate capture antibody diluted in PBS overnight at $4^{\circ} \mathrm{C}$. After blocking the plates with $1 \%$ gelatin in PBS, proper dilutions of standards and samples in $0.2 \%$ gelatin and $0.05 \%$ Tween-20 in PBS were incubated overnight at $4^{\circ} \mathrm{C}$. Then, the plates were washed with PBS containing $0.05 \%$ Tween-20, and horseradish peroxidase (HRP)-conjugated antibodies were added and incubated for $1 \mathrm{~h}$ at $37^{\circ} \mathrm{C}$. For capture, rabbit anti-human-Fc antibodies (I8010, SigmaAldrich, St. Louis, MO) were used for IgA and IgM, and goat anti-human-Fc $\gamma$ antibody (ab 98616, Abcam, Cambridge, MA) for IgG. For detection, goat antihuman-Fco-HRP (A-0295, Sigma-Aldrich) for IgA and goat anti-human-Fch-HRP (A-4290, Sigma-Aldrich) for IgM were used. Goat anti-human-Fc $\gamma$-HRP (P-0214, Dako, Glostrup, Denmark) absorbed with goat serum was used for IgG. For standard curves, solution with known concentration of colostrum-derived IgA (I-2636, Sigma-Aldrich), or IgM and IgG (Siemens Healthcare Diagnostics Products GmbH, Marburg, Germany) were used. The color reaction was developed using a solution

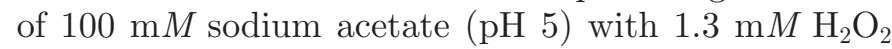
and $0.4 \mathrm{mM} 3,3^{\prime}, 5,5^{\prime}$-tetramethylbenzidine. After the addition of $2 \mathrm{~N} \mathrm{H}_{2} \mathrm{SO}_{4}$ the optical density (OD) was registered at $450 \mathrm{~nm}$ using a spectrophotometer (Titertek Multiskan Plus, Flow Laboratories, Rockville, MD).

\section{Determination of Lysozyme Activity}

The lysozyme activity was analyzed in the AF of the HM by the turbidimetric method with Micrococcus lysodeikticus as described by Trend et al. (2016), with a few modifications. Briefly, $50 \mu \mathrm{L}$ of standard lysozyme (L6876, Sigma-Aldrich) or AF of HM samples diluted in $66 \mathrm{~m} M$ potassium phosphate buffer ( $\mathrm{pH} 6.2$ ) was seeded in 96-well plates (Greiner). Then, $200 \mu \mathrm{L}$ of M. lysodeikticus (M3770, Sigma-Aldrich) previously equilibrated to $30^{\circ} \mathrm{C}$ was added and incubated for $3 \mathrm{~h}$ at $30^{\circ} \mathrm{C}$. The $\mathrm{OD}$ at $450 \mathrm{~nm}$ was registered initially and after incubation. The decrease in the OD indicates the capacity of milk to lysate $M$. lysodeikticus. Results were expressed in lysozyme units per $\mathrm{mL}$, according to the calibration curve.

\section{Evaluation of TGF- $\beta 2$ and sCD14}

The concentrations of sCD14 and TGF- 32 in the $\mathrm{AF}$ of the HM were determined by capture ELISA using Human CD14 Quantikine and Human TGF- $\beta 2$ Quantikine ELISA Kits, respectively (R\&D Systems,
Minneapolis, MN), according to the manufacturer's instructions (https://resources.rndsystems.com/pdfs/ datasheets/dy383.pdf; https://resources.rndsystems .com/pdfs/datasheets/dy302.pdf).

\section{Microbiological Analysis}

Microbiological analyses of HM were executed using media provided by Oxoid (Oxoid Ltd., Basingstoke, UK). Coliforms were assessed mixing $1.8 \mathrm{~mL}$ of each sample with $5.0 \mathrm{~mL}$ of bright green bile broth (BGB) $4 \%$ lactose in glass tubes with a bell-like compartment and then incubated for $48 \mathrm{~h}$ in an oven at $37^{\circ} \mathrm{C}$. The production of gas indicated the presence of the coli/ aerogenes group. A confirmatory test for total coliforms was performed for positive samples by incubation in BGB 5\% lactose.

Simultaneously, $100 \mu \mathrm{L}$ of direct samples and dilutions were inoculated and streaked in Petri dishes containing either tryptic soy agar as a general counting medium for aerobic bacteria (incubated $24 \mathrm{~h}$ at $37^{\circ} \mathrm{C}$ ), and violet red bile glucose agar containing lactose for total coliforms (incubated for $24 \mathrm{~h}$ at $37^{\circ} \mathrm{C}$ ). Raw milk and HoP-treated samples were incubated as positive and negative controls, respectively. All samples were analyzed in triplicate. The detection limit was considered $1.0 \log \mathrm{cfu} / \mathrm{mL}$.

\section{Statistical Analysis}

Median and interquartile range were used as descriptive measurements for immunological parameters in raw milk, and the statistical analysis was made using the Mann-Whitney test. The immunological effects by the different processing conditions were expressed in percentage of retention, calculated as the ratio between the concentration after and before treatment, multiplied by 100. Median and interquartile range were used to represent the results, and the differences were evaluated with the Wilcoxon matched-pairs signed rank test. Results for microbiological counts were represented as median with the individual values, and the difference were evaluated using the Wilcoxon matched-pairs signed rank test. Statistical significance was considered when $P$-values were below 0.05 , and was indicated with asterisks: ${ }^{*} P \leq 0.05,{ }^{* *} P \leq 0.01$. Tendencies were considered when $P$-values were between 0.05 and 0.1 . GraphPad Prism 6.01 software (demo, GraphPad Software Inc., San Diego, CA) was used for analysis.

\section{RESULTS AND DISCUSSION}

In this work we used pooled samples to minimize the high individual variability that characterizes hu- 
Table 2. Comparison of immunological components and nutritional variables between samples processed by high hydrostatic pressure (HHP) or high-pressure homogenization $(\mathrm{HPH})^{1}$

\begin{tabular}{|c|c|c|c|c|c|}
\hline Immunological component $^{2}$ & \multicolumn{2}{|c|}{$\mathrm{HHP}(\mathrm{n}=8)$} & \multicolumn{2}{|c|}{$\mathrm{HPH}(\mathrm{n}=6)$} & $P$-value \\
\hline $\operatorname{IgG}(\mu \mathrm{g} / \mathrm{mL})$ & 17.7 & $14.9-21.1$ & 21.8 & $21.3-23.5$ & 0.2394 \\
\hline Lysozyme $\left(\times 10^{3} \mathrm{LU} / \mathrm{mL}\right)$ & 6.2 & $4.6-8.2$ & 7.2 & $5.6-9.4$ & 0.4699 \\
\hline TGF- $\beta 2(\mathrm{ng} / \mathrm{mL})$ & 467.7 & $404.8-1,426.4$ & 947.1 & $420.6-1,549.1$ & 0.7306 \\
\hline Lipids (mg/mL) & 49.5 & $46.6-65.1$ & 49.5 & $46.7-59.9$ & 0.7922 \\
\hline Proteins $(\mathrm{mg} / \mathrm{mL})$ & 12.8 & $12.1-14.1$ & 12.7 & $12.1-13.8$ & 0.7792 \\
\hline Lactose $(\mathrm{mg} / \mathrm{mL})$ & 61.8 & $61.5-62.4$ & 63.8 & $62.1-65.0$ & 0.1602 \\
\hline Calories $(\mathrm{cal} / \mathrm{mL})$ & 723.0 & $701.4-884.1$ & 720.0 & $701.4-845.9$ & 0.7922 \\
\hline
\end{tabular}

${ }^{1}$ Values are expressed as median concentration and interquartile range (IQR). Mann-Whitney test was used for analysis and significant differences are indicated by $P$-values.

${ }^{2} \mathrm{LU}=$ lysozyme units; TGF- $\beta 2=$ transforming growth factor $\beta 2 ; \mathrm{sCD} 14=$ soluble cluster of differentiation 14.

man milk. Nutritional and immune composition of the samples destined to be treated by HHP or HPH are shown in Table 2 where no significant differences were observed in any parameter $(P$-values $>0.05)$. This accounted for the homogeneity of samples used to compare the technologies. In addition, the values produced were in line with those reported elsewhere (Agarwal et al., 2011).

\section{Exposure of HM to Pressure and Temperature During HoP, HHP, and HPH Processing}

Table 1 shows the main parameters describing processing by HoP, HHP, or HPH technologies. Related to HHP, when pressurizing any food matrix, one should at least expect product temperature to increase around $4^{\circ} \mathrm{C}$ per $100 \mathrm{MPa}$ applied, due to adiabatic heating (Ting et al., 2002; Patterson, 2005). This was the situation of our samples, as can be deducted from Table 1; temperature of HHP processed samples increased to a range of $21 \pm 3$ to $35 \pm 5^{\circ} \mathrm{C}$ (for all 3 pressures applied) and remained at those values until pressure was released. This temperature profiles could hardly denature immunoglobulin fractions of HM (Akazawa-Ogawa et al., 2018). Regarding HPH, this is a new nonthermal technology that is currently under study in different food systems and seems to be very promising. It is necessary to remember that there is an increment in temperature associated with the processing of samples with HPH. Based up the same principle as traditional homogenization, by the action of a positive displacement pump, the fluids are forced to pass through a narrow gap of a few micrometers in the high-pressure valve, attaining target pressure (e.g., $300 \mathrm{MPa}$ ) and decreasing sharply to atmospheric pressure (or to the pressure set at the sec- ondary valve). In addition to the increase and sudden decrease in pressure that fluid particles are exposed to, cavitation, impact, impingement, shear, and turbulence take place at the pipes downstream of the high-pressure valve, and act on the components of the fluid (Floury et al., 2002; Thiebaud et al., 2003; Floury et al., 2004). Energy is dissipated in the form of heat and heating of the fluid must be controlled to less than $0.5 \mathrm{~s}$ using a cooling system after the high-pressure valve (Datta et al., 2005; Chevalier-Lucia et al., 2011). In our case, HM samples were $\mathrm{HPH}$ processed at an inlet temperature of $20 \pm 2^{\circ} \mathrm{C}$ and the maximum temperature values reached after the high-pressure homogenizing valve were $62 \pm$ $5,64 \pm 7$, and $64 \pm 7^{\circ} \mathrm{C}$ for 200,250 , and $300 \mathrm{MPa}$, respectively. With the available cooling system, HM temperature decreased in a few seconds to $34 \pm 3,24 \pm$ 2 , and $22 \pm 2^{\circ} \mathrm{C}$ at the outlet, respectively. The effect of this sort of temperature profile on the immunological components assessed is discussed in the following section. Maximum temperatures reached by HM are on the order of those of HoP so it is reasonable to think of a thermal contribution to the effects caused by pressure and physical phenomena involved in HPH processing. Regarding HoP treatments applied to all HM pool samples, time-temperature profiles comply with international guidelines for HM banks. Even though milk temperature dropped from 62.5 to $30^{\circ} \mathrm{C}$ in approximately $6.5 \mathrm{~min}$ and to $25^{\circ} \mathrm{C}$ in approximately 12.5 min (data not shown in Table 1, illustration provided in Figure 2), time to reach target temperature and time to reach refrigerating temperatures contribute to the total effect of thermal treatment in HM immunological components. Diverse heating and cooling profiles including HTST pasteurization need to be considered for new works comparing physical processing of HM. 


\section{Effects of HPH on Microbiological Markers and Immunological Components}

Figure 3 shows the results obtained for microbiological count of HM samples processed using HPH and HoP. Total counts obtained for all pressures tested were significantly lower $(P \leq 0.01)$ than control and raw HM samples (control machine samples values correspond to raw HM samples pumped through the HPH equipment at atmospheric pressure). These HPH pressure conditions were less efficient in destroying aerobic bacteria than HoP. Median coliform counts at all pressure levels assessed (200, 250, and $300 \mathrm{MPa}$ ) were below the detection limit $(1.0 \log \mathrm{cfu} / \mathrm{mL})$; further incubation of the samples in enrichment broth confirmed the absence of coliforms in HM processed by HPH and HoP (Figure $3)$. No previous work has reported the effect of $\mathrm{HPH}$ on HM, but several authors demonstrated the positive effect of HPH in the inactivation of spoilage or pathogenic microorganisms in bovine milk, similar to our findings in HM. Microbial reductions of $3.0 \log \mathrm{cfu} / \mathrm{mL}$ were reported when processing milk using $\mathrm{HPH}$ at 250 $\mathrm{MPa}$ and inlet temperature of $45^{\circ} \mathrm{C}$ (Hayes et al., 2005). Pereda et al. (2006) reported a reduction of $4.0 \mathrm{log} \mathrm{cfu} /$ $\mathrm{mL}$ at $300 \mathrm{MPa}$ for inlet temperatures of 30 and $40^{\circ} \mathrm{C}$.

The values of retention of different immunological components studied at different HPH pressures (200, 250 , and $300 \mathrm{MPa}$ ), and inlet temperature of $20 \pm 2^{\circ} \mathrm{C}$ are shown in Table 3. For control samples (raw HM circulated through the HPH equipment without increasing pressure), a certain reduction in the retention of the immunological components was already produced. The retention values obtained for $\operatorname{Ig} \mathrm{A}$ showed a decreasing tendency as HPH treatment pressure increased $(0.05<$ $P \leq 0.1$ ). The pattern of retentions observed for IgM was similar to that obtained for IgA. As expected, IgM retention was negatively affected by HoP. The retentions obtained for IgM in HM processed using $\mathrm{HPH}$ $\leq 250 \mathrm{MPa}$ were significantly higher than those observed in HM processed by HoP, reaching a retention of $93 \%$ when $200 \mathrm{MPa}$ of pressure was applied. The retentions observed for IgG were similar to the ones obtained for IgA and IgM, only showing a significant loss when HM was processed using $\mathrm{HPH}$ at $300 \mathrm{MPa}$. In all cases, for pressures of $300 \mathrm{MPa}$ the retentions observed were not significantly different than those obtained when HM was processed by HoP. Lysozyme activity also showed a decreasing tendency with increasing HPH processing pressure, reaching similar values for HoP. For sCD14 the retentions decreased significantly with pressure, being samples processed at $200 \mathrm{MPa}$ not significantly different from control, and for $300 \mathrm{MPa}$ showed minimal but still significantly higher value than the retention for HoP. Retentions found for TGF- $\beta 2$ were not signifi- cantly different from the ones found in HM processed by HoP, with the exception of HM milk processed using pressure at $300 \mathrm{MPa}$, in which the retention value obtained was significantly poorer.

Altogether, our results show that the main advantages of $\mathrm{HPH}$ in relation to $\mathrm{HoP}$ are related to the retention of antibodies and sCD14 when processing $\mathrm{HM}$ at pressures up to $250 \mathrm{MPa}$, with similar results between processing methods for lysozyme and TGF- $\beta 2$ at these conditions.

As seen in Table 1, the ranges of maximum temperatures reached immediately after HM passed through the gap of the high-pressure valve are in the order or above the target temperature for HoP. This may partially explain the similarities between the retention values obtained with $\mathrm{HoP}$ and $\mathrm{HPH}$ at $300 \mathrm{MPa}$, even when the time the sample remains at these temperatures is less than $1 \mathrm{~s}$ versus $30 \mathrm{~min}$ for HoP. It has been previously reported that immunoglobulins (in particular $\operatorname{IgG}$ ) start denaturation at $65^{\circ} \mathrm{C}$, but $\operatorname{IgA}$ and $\operatorname{IgM}$ are more sensitive to heat treatment, reaching $75 \%$ of denaturalization at $72^{\circ} \mathrm{C}$ after 5 and $1.5 \mathrm{~min}$ in bovine milk, respectively (Akazawa-Ogawa et al., 2018). Thus, this might partially explain the pattern observed regardless of the effect of the other physical phenomena that take place after the fluid traverses the high-pressure valve. Other factors such as valve design might also be considered. Faster and more efficient cooling systems after the high-pressure valve might make a difference in HPH processing of HM and other protein matrices. The advantages of HPH are linked to the possibility of using larger samples of HM, processing HM in a continuous manner, and the possibility of coupling aseptic filling of sterile bottles (Guamis Lopez et al., 2015). The HPH equipment is traditionally capable of working with flows ranging from 8 to $120 \mathrm{~L} / \mathrm{h}$; in particular benchtop systems designed to process $10 \mathrm{~L} / \mathrm{h}$ maximum and coupled to aseptic filling cabins are commercially available. Nowadays, more robust equipment with very efficient cooling systems after the high-pressure valve is being manufactured. To our knowledge, this is the first manuscript reporting the effect of $\mathrm{HPH}$ processing of HM. Further studies covering fluid inlet temperatures below $15^{\circ} \mathrm{C}$ or at refrigeration conditions need to be performed. No previous reports are available stating the effect or biological meaning of this higher retention of the immunological components assessed.

\section{Effects of HHP on Microbiological Markers and Immunological Components}

Figure 3 shows total counts and coliform counts of HM samples processed by HHP. We found that all pressures tested (400, 450, and $500 \mathrm{MPa}$ ) seemed to be efficient 


\section{HHP}

\section{Aerobic bacteria}

TSA count

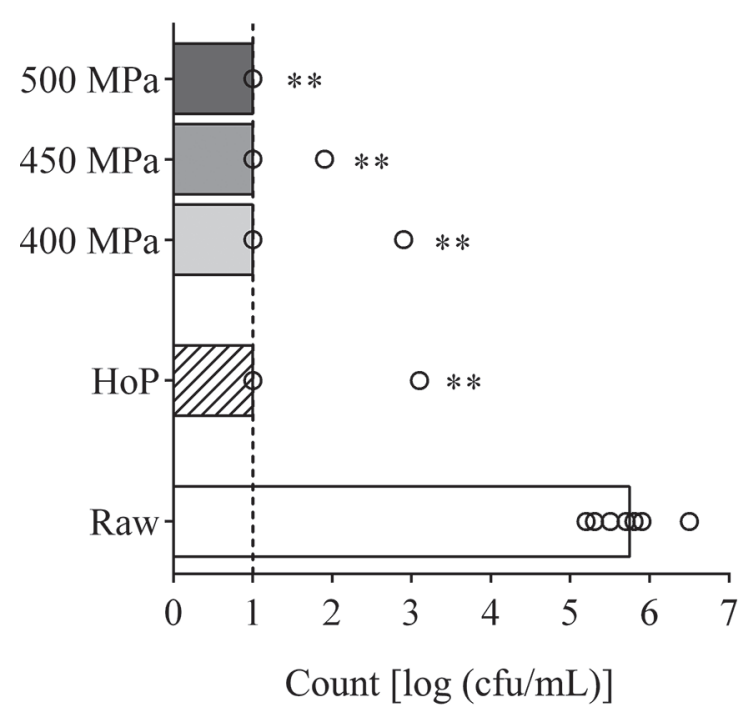

\section{HPH}

\section{Aerobic bacteria}

\section{TSA count}

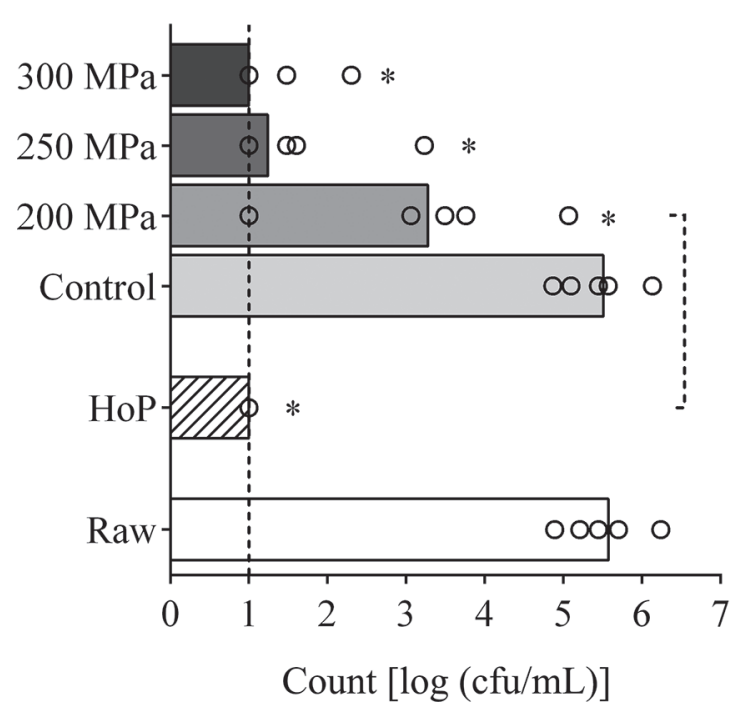

\section{Coliforms}

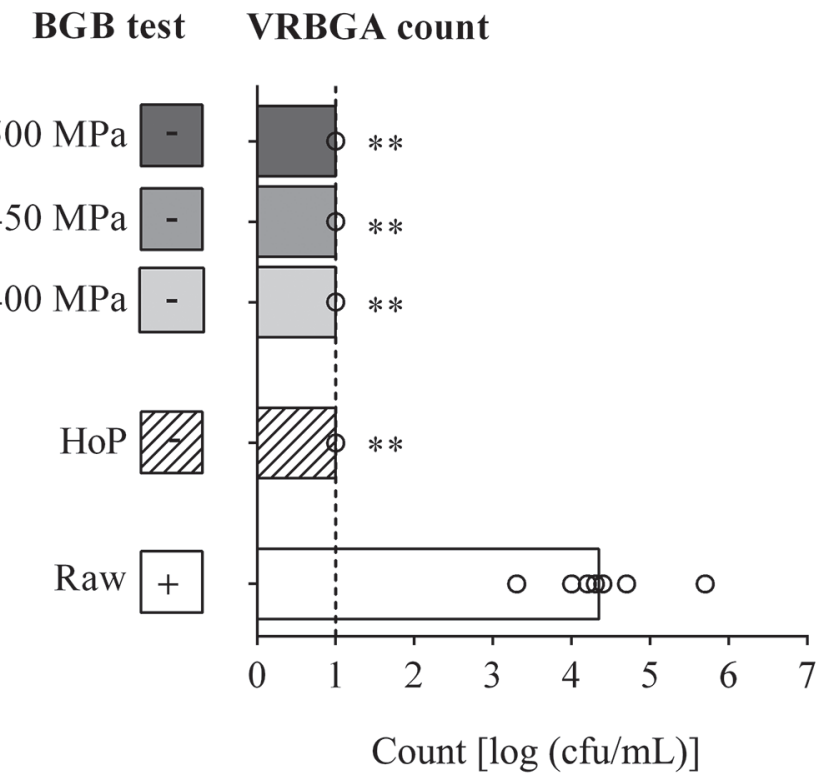

\section{Coliforms}

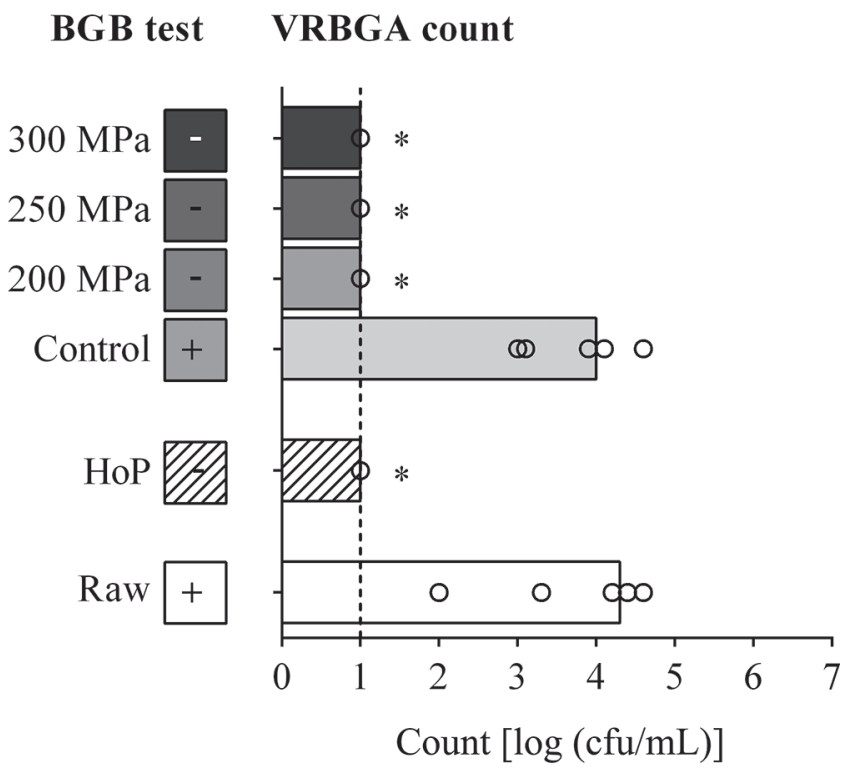

Figure 3. Effects on total count (tryptic soy agar) and coliform count (violet red bile glucose agar; VRBGA) for samples treated with high hydrostatic pressure (HHP) and high-pressure homogenization (HPH), compared with raw and Holder pasteurization (HoP) samples. Bars indicate median values and dots indicate individual results obtained for each experiment (HHP, $\mathrm{n}=8 ; \mathrm{HPH}, \mathrm{n}=6)$. Significant differences were indicated with asterisks on bars $\left({ }^{*} P \leq 0.05\right.$ or ${ }^{* *} P \leq 0.01$, Wilcoxon matched-pairs signed rank test). Absences of colonies on tryptic soy agar (TSA) or VRBGA plates were indicated as the detection limit (1.0 log cfu/mL). BGB = bright green bile broth. 


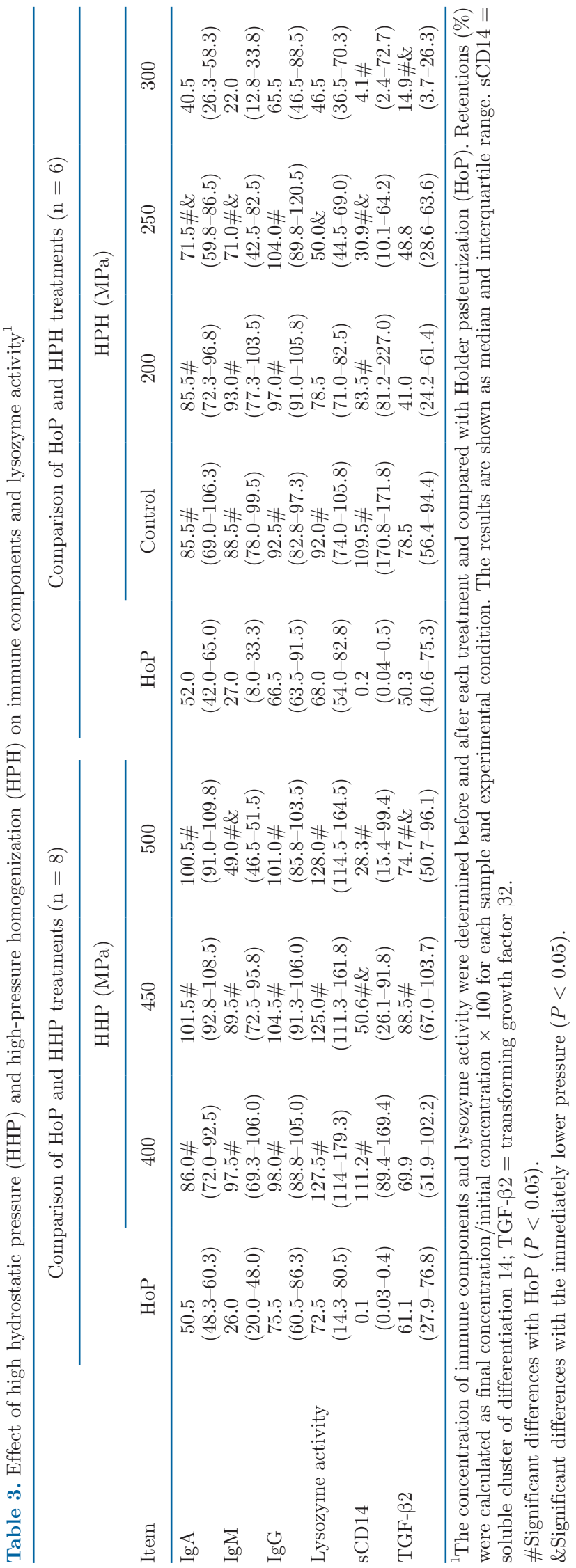

at destroying coliforms in HM, achieving both HHP and HoP levels below the quantification limit (1.0 log cfu/ $\mathrm{mL}$ ) and absence after incubation of BGB. Regarding total counts, HHP treatments significantly differ from those obtained for raw milk $(P<0.05)$. Median total counts obtained for HHP-treated samples at 400, 450, and $500 \mathrm{MPa}$ were equal to median counts obtained for samples treated with HoP. Our results were consistent with previous reports showing that the HPP processing of $\mathrm{HM}$ at $400 \mathrm{MPa}$ and $12^{\circ} \mathrm{C}$ for 5 min reduced total Enterobacteriaceae counts to undetectable levels (below $1.0 \log \mathrm{cfu} / \mathrm{mL}$; Permanyer et al., 2010).

The retentions of $\operatorname{Ig} \mathrm{A}, \operatorname{IgM}, \operatorname{IgG}$, lysozyme, sCD14, and TGF- $\beta 2$ were assessed to produce a comprehensive picture of the preservation of immunological components in HM.

The results obtained for immunological components in samples processed by HHP were encouraging, as seen in Table 3. The retention values obtained for the studied immunoglobulins were significantly higher in HM samples treated with HHP than in the ones treated with HoP for all cases except for TGF- $\beta 2$. Immunoglobulins react to thermal processes in varied ways but always losing activity (Li-Chan et al., 1995; Dominguez et al., 1997; Chen et al., 2000). The IgA, IgM, and IgG retentions in HM samples processed using HHP were at least $35.5,23$, and $22.5 \%$ higher than HM samples processed by HoP, respectively. Overall, IgA and $\mathrm{IgG}$ retentions in HM milk processed using HHP at $\geq 400$ $\mathrm{MPa}$ were close to $100 \%$. Previous studies observed relatively high stability of human IgG to processing by HHP up to $500 \mathrm{MPa}$ for $5 \mathrm{~s}$ because $\operatorname{IgG}$ barely modifies its Y-shape structure toward a symmetric T without unfolding (König et al., 2017). The deleterious effect produced for IgM was notorious when processing $\mathrm{HM}$ by HoP and HHP at $500 \mathrm{MPa}$. The IgM retention values went from a maximum value of $97.5 \%$ in milk processed using HHP at 400 , to $49 \%$ at $500 \mathrm{MPa}$. Our findings agree with the few studies carried out where the effects of different levels of HHP on HM were explored showing certain advantages over HoP. Individual samples of mature $\mathrm{HM}$ processed at 400, 500, and 600 $\mathrm{MPa}$ for 5 min at $12^{\circ} \mathrm{C}$ showed a $100 \%$ retention of total IgA at $400 \mathrm{MPa}$, compared with $50.5 \%$ corresponding to conventional pasteurization; $500 \mathrm{MPa}$ produced an IgA retention of $100.5 \%$ whereas the application of 600 $\mathrm{MPa}$ resulted in losses (data not shown) comparable to those obtained with HoP (Permanyer et al., 2010). Consistently, regarding the immunological components of the milk, after HHP treatment at $400 \mathrm{MPa}$ and $10^{\circ} \mathrm{C}$ for 3 or $6 \mathrm{~min}$, the original levels of $\mathrm{IgM}$, $\operatorname{IgA}$, and IgG were maintained (Contador et al., 2013). The contents of vitamins and fatty acids has also been analyzed and the results were also very encouraging, 
presenting no significant variation in the concentration of ascorbic acid and total vitamin $\mathrm{C}$ (ascorbic acid plus dehydroascorbic acid) after applying HHP versus HoP where $20 \%$ and $16 \%$ loss were observed, respectively (Moltó-Puigmartí et al., 2011). Viazis et al. (2007) studied the changes in IgA immunoreactivity against Escherichia coli antigens in a HMB milk sample subjected to $400 \mathrm{MPa}$ for various periods of time (30-120 min, maximum temperature $31^{\circ} \mathrm{C}$ ), and observed that the retention was always significantly higher compared with the samples subjected to thermal treatments (approximately $75-86 \%$ vs. $51 \%$, respectively), the losses being proportional to time. It is unknown whether modifications caused by HHP in immunoglobulins alter differential reactivity against relevant pathogens. Modifications produced by HHP are known to reduce allergenic properties of dietary proteins present in HM, as occurs with bovine $\beta$-LG (Meng et al., 2017) and soy proteins ( $\mathrm{Li}$ et al., 2018).

The processing of HM using HHP protected the intrinsic antimicrobial properties of milk as lysozyme activity was significantly higher $(P \leq 0.01)$ in samples processed by HHP than the ones processed by HoP for all conditions tested. These results are in line with those previously reported by Sousa et al. (2014) who found that it was possible to retain original lysozyme activity in all HHP conditions tested, whereas the lysozyme activity obtained in samples processed by HoP dropped approximately $56 \%$.

In addition to components involved in child defenses, we considered 2 immune factors implicated in immunoregulation. Soluble cluster of differentiation 14 is particularly interesting for its role in modulating inflammation caused by LPS from microbiota or pathogens in the gut (Patel and Kim, 2018). Soluble cluster of differentiation 14 was completely depleted after HM was processed by HoP, whereas the retention was complete $(111.2 \%)$ in HM processed using HHP at $400 \mathrm{MPa}$, and decreased to 50.6 and $28.3 \%$ after processing at 450 and $500 \mathrm{MPa}$, respectively. The HHP processing of HM at $450 \mathrm{MPa}$ became also advantageous for preserving TGF- 32 in comparison with HoP, with 88.5 versus $61.1 \%$ of retention in HM, respectively. Globally, our results indicate that the immunoregulatory properties of mature HM can be better preserved by processing using HHP than HoP. In the vulnerable conditions of preterm newborns, which are highly susceptible to gut inflammation, the presence of higher levels of sCD14 and TGF- $\beta 2$ are relevant. Both immune factors have been linked to the prevention of inflammatory disease including necrotizing enterocolitis (Patel and Kim, 2018).

The HHP processing vessels typically range from 50 to $600 \mathrm{~L}$ and the process is carried out in batches of packaged/bottled foods, preventing recontamination. In the last $20 \mathrm{yr}$, HHP has been widely adopted by the food industry. Being a discontinuous process typically carried out in lots, it is not widely used for processing milk or traditional dairy products (milk pasteurizers typically have capacities of 5,000 to $50,000 \mathrm{~L} / \mathrm{h}$ running for several hours without stopping). However, the protection of colostrum from microbiological alteration and the preservation of immunological components is a niche of dairy applications where HHP has unique advantages (Borad and Singh, 2018). Furthermore, HHP allows the preservation of HM samples from individual donors. For all 3 pressures tested $(400,450$, and 500 $\mathrm{MPa}, 5 \mathrm{~min}, 20^{\circ} \mathrm{C}$ ), microbial reductions for coliforms to undetectable levels (similar to HoP) were achieved, and also higher levels of immunological component retention were reached.

\section{CONCLUSIONS}

The results of the microbiological and immunological indicators for HHP (400 to $500 \mathrm{MPa}$ for $5 \mathrm{~min}$ at $20^{\circ} \mathrm{C}$ ) and $\mathrm{HPH}\left(250 \mathrm{MPa}\right.$ at inlet temperature of $\left.20^{\circ} \mathrm{C}\right)$ are encouraging. Nonetheless, it is not clear whether the higher percentages of retention achieved have a significant effect on the health of the infant. The results obtained in this paper and former works performed by other research teams, underline the advantages of using HHP for preserving donated HM. One of the drawbacks of HHP is the cost of the units, mainly designed for industrial facilities rather than hospitals. Nevertheless, from the engineering point of view there are no constraints preventing downsizing to pressurizing chambers of smaller volumes (i.e., $20 \mathrm{~L}$ ) to adjust volumes to those handled in HMB (i.e., batches of 12 to $16 \mathrm{~L}$ per day, loading HHP vessel up to 50 to $70 \%$ of its volume). The price could be still above new HoP units, but the benefits might justify the investment. Regarding HPH, one of the limitations to its application is the need of generating a minimum volume of pooled HM. This is necessary to allow continuous processing and to cover up for residence times of HM in the whole homogenizer (inlet, pipes, valves, outlet, in the order of a few seconds, accounting for approximately $100 \mathrm{~mL}$ ) warranting that once the homogenizer reaches target pressure the whole fluid is correctly pressurized. At present, both big industries and small start-ups are developing more robust and stable HPH equipment preventing pressure variations at the high-pressure valves, fitted with very efficient cooling devices avoiding thermal damage of the components of the fluid. It might be worthy to carry out new experiments using modern HPH equipment, optimizing processing conditions or using lower inlet temperatures and covering effects on other targets such 
as bacterial spores, viruses frequently found in HM, the likely survival of native bacteria with potentially beneficial effects on health, and the retention or inactivation of endogenous enzyme activities.

\section{ACKNOWLEDGMENTS}

The authors thank the donors of milk samples and the technical staff of the HMB of the Pereira Rossell Hospital (Montevideo, Uruguay) for invaluable collaboration. This work was supported by the Consejo Sectorial de Investigación Científica, Universidad de la República, Uruguay (Grant CSIC ID3-2014 to Tomás López-Pedemonte and Ana Hernández) and the Programa de Desarrollo de las Ciencias Básicas (PEDECIBA, Montevideo, Uruguay). The authors have not stated any conflicts of interest.

\section{REFERENCES}

Affolter, M., C. L. Garcia-Rodenas, G. Vinyes-Pares, R. Jenni, I. Roggero, O. Avanti-Nigro, C. de Castro, A. Zhao, Y. Zhang, P. Wang, S. K. Thakkar, and L. Favre. 2016. Temporal changes of protein composition in breast milk of Chinese urban mothers and impact of caesarean section delivery. Nutrients 8:504. https://doi.org/10 $.3390 / \mathrm{nu} 8080504$.

Agarwal, S., W. Karmaus, S. Davis, and V. Gangur. 2011. Immune markers in breast milk and fetal and maternal body fluids: A systematic review of perinatal concentrations. J. Hum. Lact. 27:171186. https://doi.org/10.1177/0890334410395761.

Agência Nacional de Vigilância Sanitaria. 2008. Banco de Leche Humana, Funcionamiento, Prevención y Control de Riesgos. 1st ed. Brasília, Brazil.

Akazawa-Ogawa, Y., H. Nagai, and Y. Hagihara. 2018. Heat denaturation of the antibody, a multi-domain protein. Biophys. Rev. 10:255-258. https://doi.org/10.1007/s12551-017-0361-8.

Amador-Espejo, G. G., J. J. Gallardo-Chacon, H. Nykänen, B. Juan, and A. J. Trujillo. 2015. Effect Of ultra high-pressure homogenization on hydro- and liposoluble milk vitamins. Food Res. Int. 77:49-54. https://doi.org/10.1016/j.foodres.2015.04.025.

Amador-Espejo, G. G., A. Suàrez-Berencia, B. Juan, M. E. Bárcenas, and A. J. Trujillo. 2014. Effect of moderate inlet temperatures in ultra-high-pressure homogenization treatments on physicochemical and sensory characteristics of milk. J. Dairy Sci. 97:659-671. https://doi.org/10.3168/jds.2013-7245.

Arnold, L. D. W. 2006. Global health policies that support the use of banked donor human milk: A human rights issue. Int. Breastfeed. J. 1:26. https://doi.org/10.1186/1746-4358-1-26.

Baroncelli, S., C. M. Galluzzo, G. Liotta, M. Andreotti, F. Ciccacci, S. Mancinelli, V. T. Tolno, J. Gondwe, R. Amici, M. C. Marazzi, S. Vella, M. Giuliano, L. Palombi, and L. Palmisano. 2018. Soluble CD14 levels in plasma and breastmilk of Malawian HIV+ women: Lack of association with morbidity and mortality in their exposed infants. Am. J. Reprod. Immunol. 79:e12812. https://doi.org/10 $.1111 /$ aji.12812.

Borad, S. G., and A. K. Singh. 2018. Colostrum immunoglobulins: Processing, preservation and application aspects. Int. Dairy J. 85:201-210. https://doi.org/10.1016/j.idairyj.2018.05.016.

Briñez, W. J., A. X. Roig-Sagués, M. M. Hernández Herrero, and B. Guamis López. 2006. Inactivation of Listeria innocua in milk and orange juice by ultrahigh-pressure homogenization. J. Food Prot. 69:86-92. https://doi.org/10.4315/0362-028X-69.1.86.

Cheftel, J. C. 1995. Review: High-pressure, microbial inactivation and food preservation. Food Sci. Technol. Int. 1:75-90. https://doi .org/10.1177/108201329500100203.
Chen, C. C., Y. Y. Tu, and H.-M. Chang. 2000. Thermal stability of bovine milk immunoglobulin $\mathrm{G}$ ( $\mathrm{IgG}$ ) and the effect of added thermal protectants on the stability. J. Food Sci. 65:188-193. https:// doi.org/10.1111/j.1365-2621.2000.tb15977.x.

Chevalier-Lucia, D., C. Blayo, A. Gràcia-Julià, L. Picart-Palmade, and E. Dumay. 2011. Processing of phosphocasein dispersions by dynamic high pressure: Effects on the dispersion physico-chemical characteristics and the binding of $\alpha$-tocopherol acetate to casein micelles. Innov. Food Sci. Emerg. Technol. 12:416-425. https://doi .org/10.1016/j.ifset.2011.07.007.

Contador, R., J. Delgado-Adámez, F. J. Delgado, R. Cava, and R. Ramírez. 2013. Effect of thermal pasteurisation or high pressure processing on immunoglobulin and leukocyte contents of human milk. Int. Dairy J. 32:1-5. https://doi.org/10.1016/j.idairyj.2013 .03 .006 .

Datta, N., M. G. Hayes, H. C. Deeth, and A. L. Kelly. 2005. Significance of frictional heating for effects of high pressure homogenisation on milk. J. Dairy Res. 72:393-399. https://doi.org/10.1017/ S0022029905001056.

Delgado, F. J., R. Contador, A. Álvarez-Barrientos, R. Cava, J. Delgado-Adámez, and R. Ramírez. 2013. Effect of high pressure thermal processing on some essential nutrients and immunological components present in breast milk. Innov. Food Sci. Emerg. Technol. 19:50-56. https://doi.org/10.1016/j.ifset.2013.05.006.

Dominguez, E., M. D. Perez, and M. Calvo. 1997. Effect of heat treatment on the antigen-binding activity of anti-peroxidase immunoglobulins in bovine colostrum. J. Dairy Sci. 80:3182-3187. https:/ /doi.org/10.3168/jds.S0022-0302(97)76290-8.

Dumay, E., D. Chevalier-Lucia, L. Picart-Palmade, A. Benzaria, A. Gràcia-Julià, and C. Blayo. 2013. Technological aspects and potential applications of (ultra) high-pressure homogenisation. Trends Food Sci. Technol. 31:13-26. https://doi.org/10.1016/j.tifs.2012.03 .005 .

Eidelman, A. I., and R. J. Schanler. 2012. Breastfeeding and the use of human milk. Pediatrics 129:e827-e841. https://doi.org/10.1542/ peds.2011-3552.

Escuder-Vieco, D., I. Espinosa-Martos, J. M. Rodríguez, L. Fernández, and C. R. Pallás-Alonso. 2018. Effect of HTST and holder pasteurization on the concentration of immunoglobulins, growth factors, and hormones in donor human milk. Front. Immunol. 9:2222. https://doi.org/10.3389/fimmu.2018.02222.

Evelyn, F., and V. M. Silva. 2019. Heat assisted HPP for the inactivation of bacteria, moulds and yeasts spores in foods: Log reductions and mathematical models. Trends Food Sci. Technol. 88:143-156. https://doi.org/10.1016/j.tifs.2019.03.016.

Floury, J., J. Bellettre, J. Legrand, and A. Desrumaux. 2004. Analysis of a new type of high pressure homogeniser. A study of the flow pattern. Chem. Eng. Sci. 59:843-853. https://doi.org/10.1016/j .ces.2003.11.017.

Floury, J., A. Desrumaux, and J. Legrand. 2002. Effect of ultra-highpressure homogenization on structure and on rheological properties of soy protein-stabilized emulsions. J. Food Sci. 67:3388-3395. https://doi.org/10.1111/j.1365-2621.2002.tb09595.x.

Gervilla, R., V. Ferragut, and B. Guamis. 2000. High pressure inactivation of microorganisms inoculated into ovine milk of different fat contents. J. Dairy Sci. 83:674-682. https://doi.org/10.3168/jds .S0022-0302(00)74928-9.

Giribaldi, M., A. Coscia, C. Peila, S. Antoniazzi, C. Lamberti, M. Ortoffi, G. E. Moro, E. Bertino, T. Civera, and L. Cavallarin. 2016. Pasteurization of human milk by a benchtop high-temperature short-time device. Innov. Food Sci. Emerg. Technol. 36:228-233. https://doi.org/10.1016/j.ifset.2016.07.004.

Guamis Lopez, B., A. J. T. M. Buenaventura, V. F. Perez, M. Q. T. Joan, J. L. P. Tomás, and N. B. D. Martin. 2015. Continuous system and procedure of sterilization and physical stabilization of pumpable fluids by means of an ultra-high pressure homogenization. Patent Application WO2012010284A2.

Hartmann, B. T., W. W. Pang, A. D. Keil, P. E. Hartmann, and K. Simmer. 2007. Best practice guidelines for the operation of a donor human milk bank in an Australian NICU. Early Hum. Dev. 83:667-673. https://doi.org/10.1016/j.earlhumdev.2007.07.012. 
Hayes, M. G., P. F. Fox, and A. L. Kelly. 2005. Potential applications of high pressure homogenisation in processing of liquid milk. J. Dairy Res. 72:25-33. https://doi.org/10.1017/S0022029904000524.

IDF. 1974. IDF 28A: Determination of the lactose content of milk. International Dairy Federation, Belgium.

ISO. 2010. ISO 1211/IDF 1: Milk - Determination of fat content Gravimetric method (Reference method). International Organization for Standardization, Geneva, Switzerland.

ISO. 2014. ISO 8968/IDF 20: Milk and milk products - Determination of nitrogen content - Part 1: Kjeldahl principle and crude protein calculation. International Organization for Standardization, Geneva, Switzerland

Koenig, Á., E. Maria de Albuquerque Diniz, S. França Correia Barbosa, and F. Adolfo Costa Vaz. 2005. Immunologic factors in human milk: The effects of gestational age and pasteurization. J. Hum. Lact. 21:439-443. https://doi.org/10.1177/0890334405280652.

Kondo, N., Y. Suda, A. Nakao, K. Oh-Oka, K. Suzuki, K. Ishimaru, M. Sato, T. Tanaka, A. Nagai, and Z. Yamagata. 2011. Maternal psychosocial factors determining the concentrations of transforming growth factor-beta in breast milk. Pediatr. Allergy Immunol. 22:853-861. https://doi.org/10.1111/j.1399-3038.2011.01194.x.

König, N., M. Paulus, K. Julius, J. Schulze, M. Voetz, and M. Tolan. 2017. Antibodies under pressure: A small-angle X-ray scattering study of immunoglobulin G under high hydrostatic pressure. Biophys. Chem. 231:45-49. https://doi.org/10.1016/j.bpc.2017.05 .016 .

Lawrence, R. M., and C. A. Pane. 2007. Human breast milk: Current concepts of immunology and infectious diseases. Curr. Probl. Pediatr. Adolesc. Health Care 37:7-36. https://doi.org/10.1016/j .cppeds.2006.10.002.

Li, H., Y. Jia, W. Peng, K. Zhu, H. Zhou, and X. Guo. 2018. High hydrostatic pressure reducing allergenicity of soy protein isolate for infant formula evaluated by ELISA and proteomics via Chinese soy-allergic children's sera. Food Chem. 269:311-317. https://doi .org/10.1016/j.foodchem.2018.07.001

Li-Chan, E., A. Kummer, J. N. Losso, D. D. Kitts, and S. Nakai. 1995. Stability of bovine immunoglobulins to thermal treatment and processing. Food Res. Int. 28:9-16. https://doi.org/10.1016/ 0963-9969(95)93325-O.

Meng, X., Y. Bai, J. Gao, X. Li, and H. Chen. 2017. Effects of high hydrostatic pressure on the structure and potential allergenicity of the major allergen bovine $\beta$-lactoglobulin. Food Chem. 219:290296. https://doi.org/10.1016/j.foodchem.2016.09.153.

Moltó-Puigmartí, C., M. Permanyer, A. I. Castellote, and M. Carmen López-Sabater. 2011. Effects of pasteurisation and high-pressure processing on vitamin $\mathrm{C}$, tocopherols and fatty acids in mature human milk. Food Chem. 124:697-702. https://doi.org/10.1016/j .foodchem.2010.05.079.

Murchie, L. W., M. Cruz-Romero, J. P. Kerry, M. Linton, M. F. Patterson, M. Smiddy, and A. L. Kelly. 2005. High pressure processing of shellfish: A review of microbiological and other quality aspects. Innov. Food Sci. Emerg. Technol. 6:257-270. https://doi.org/10 .1016/j.ifset.2005.04.001.

Oddy, W. H., and F. Rosales. 2010. A systematic review of the importance of milk TGF- $\beta$ on immunological outcomes in the infant and young child. Pediatr. Allergy Immunol. 21(1 PART I):47-59. https://doi.org/10.1111/j.1399-3038.2009.00913.x.

Patel, A. L., and J. H. Kim. 2018. Human milk and necrotizing enterocolitis. Semin. Pediatr. Surg. 27:34-38. https://doi.org/10.1053/j .sempedsurg.2017.11.007.

Patterson, M. F. 2005. Microbiology of pressure-treated foods. J. Appl. Microbiol. 98:1400-1409. https://doi.org/10.1111/j.1365 $-2672.2005 .02564 . x$

Patterson, M. F., and D. J. Kilpatrick. 1998. The combined effect of high hydrostatic pressure and mild heat on inactivation of patho- gens in milk and poultry. J. Food Prot. 61:432-436. https://doi .org/10.4315/0362-028X-61.4.432.

Pereda, J., V. Ferragut, B. Guamis, and A. J. Trujillo. 2006. Effect of ultra high-pressure homogenisation on natural-occurring microorganisms in bovine milk. IUFoST 1341-42. https://doi.org/10 .1051/IUFoST:20060250.

Permanyer, M., C. Castellote, C. Ramírez-Santana, C. Audí, F. J. Pérez-Cano, M. Castell, M. C. López-Sabater, and À. Franch. 2010. Maintenance of breast milk immunoglobulin a after highpressure processing. J. Dairy Sci. 93:877-883. https://doi.org/10 $.3168 /$ jds.2009-2643.

Pineda, R. 2011. Direct breast-feeding in the neonatal intensive care unit: Is it important. J. Perinatol. 31:540-545. https://doi.org/10 $.1038 /$ jp.2010.205.

Rodríguez-Camejo, C., A. Puyol, L. Fazio, E. Villamil, P. Arbildi, C. Sóñora, M. Castro, L. Carroscia, and A. Hernández. 2020. Impact of holder pasteurization on immunological properties of human breast milk over the first year of lactation. Pediatr. Res. https:// doi.org/10.1038/s41390-019-0500-y.

Romeu-Nadal, M. A. I. Castellote, A. Gayà, and M. C. López-Sabater. 2008. Effect of pasteurisation on ascorbic acid, dehydroascorbic acid, tocopherols and fatty acids in pooled mature human milk. Food Chem. 107:434-438. https://doi.org/10.1016/j.foodchem .2007.06.060.

Sousa, S. G., I. Delgadillo, and J. A. Saraiva. 2014. Effect of thermal pasteurisation and high-pressure processing on immunoglobulin content and lysozyme and lactoperoxidase activity in human colostrum. Food Chem. 151:79-85. https://doi.org/10.1016/j.foodchem 2013.11.024.

Thiebaud, M., E. Dumay, L. Picart, J. P. Guiraud, and J. C. Cheftel. 2003. High-pressure homogenisation of raw bovine milk. Effects on fat globule size distribution and microbial inactivation. Int. Dairy J. 13:427-439. https://doi.org/10.1016/S0958-6946(03)00051-7.

Ting, E., V. M. Balasubramaniam, and E. Raghubeer. 2002. Determining thermal effects in high-pressure processing. Food Technol. 56:31-35.

Trend, S., T. Strunk, M. L. Lloyd, C. H. Kok, J. Metcalfe, D. T. Geddes, C. T. Lai, P. Richmond, D. A. Doherty, K. Simmer, and A. Currie. 2016. Levels of innate immune factors in preterm and term mothers' breast milk during the 1st month postpartum. Br. J. Nutr. 115:1178-1193. https://doi.org/10.1017/S0007114516000234.

Updegrove, K. 2005. Human Milk Banking in the United States. Newborn Infant Nurs. Rev. 5(1 SPEC. ISS.):27-33. https://doi.org/10 $.1053 /$ j.nainr.2005.02.005

Vachon, J. F., E. E. Kheadr, J. Giasson, P. Paquin, and I. Fliss. 2002. Inactivation of foodborne pathogens in milk using dynamic high pressure. J. Food Prot. 65:345-352. https://doi.org/10.4315/0362 $-028 \mathrm{X}-65.2 .345$

Viazis, S., B. E. Farkas, and J. C. Allen. 2007. Effects of high-pressure processing on immunoglobulin A and lysozyme activity in human milk. J. Hum. Lact. 23:253-261. https://doi.org/10.1177/ 0890334407303945

Weaver, L. T. 1997. Significance of bioactive substances in milk to the human neonate. Livest. Prod. Sci. 50:139-146. https://doi.org/10 .1016/S0301-6226(97)00084-5.

\section{ORCIDS}

A. Irazusta @ https://orcid.org/0000-0002-6446-1979

C. Rodríguez-Camejo @ https://orcid.org/0000-0002-1348-8012

S. Jorcin (ํ) https://orcid.org/0000-0002-7388-7031

A. Hernández (1) https://orcid.org/0000-0001-5189-0208

T. López-Pedemonte @ https://orcid.org/0000-0002-1512-7536 


\section{APPENDIX}

A
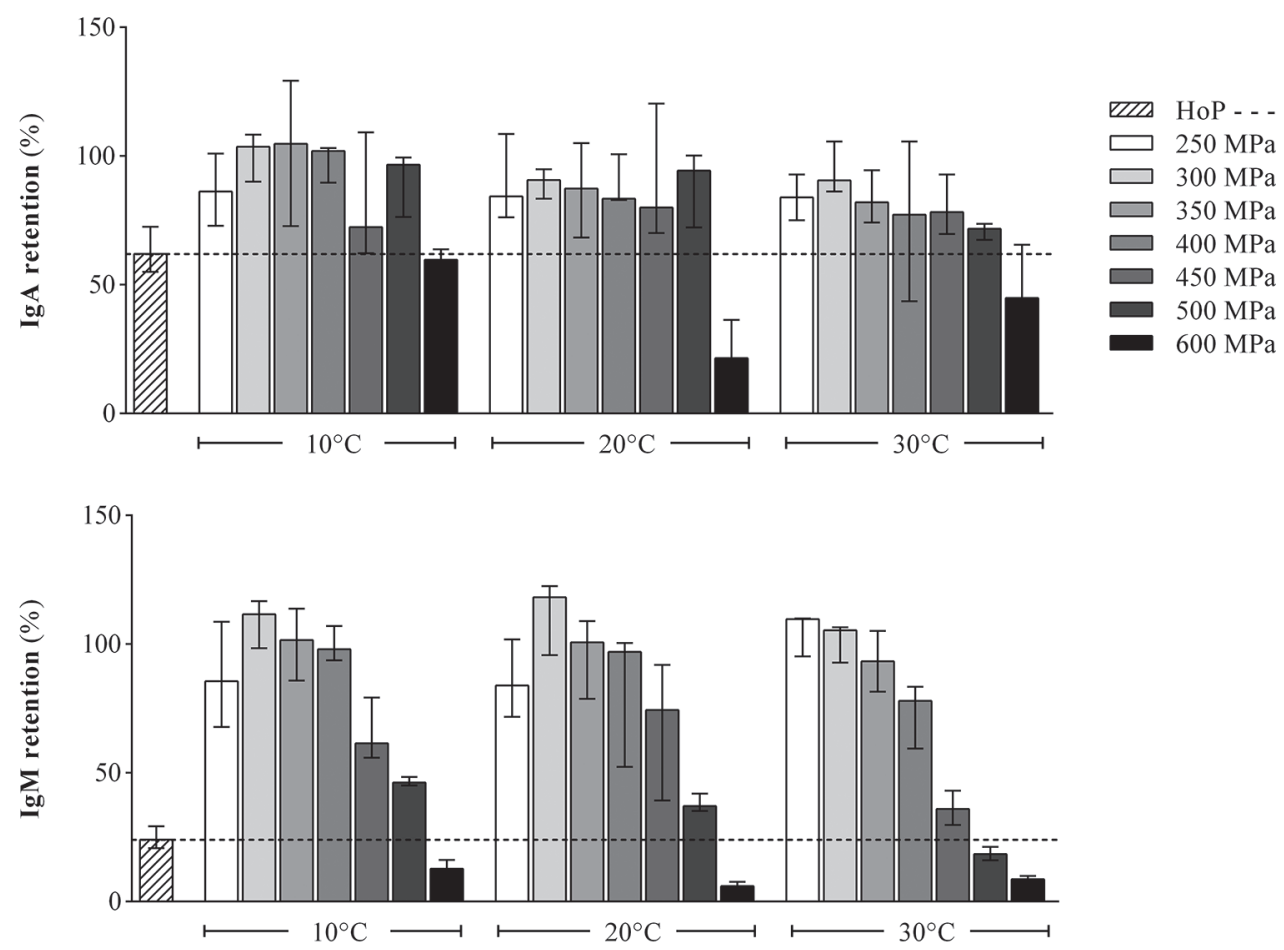

B

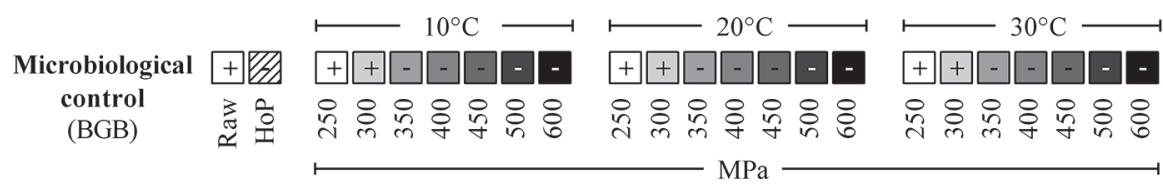

Figure A1. Effect of the processing of human milk samples by high hydrostatic pressure (HHP) and temperature on IgA and IgM retention. Values are expressed as the median, and error bars stand for interquartile range $(\mathrm{n}=6)$. (A) IgA and IgM concentrations were determined before and after treatment with HHP and Holder pasteurization (HoP; dotted line). (B) For each experimental condition, coliform detection is indicated as \pm according to gas production. $\mathrm{BGB}=$ bright green bile broth. 